\title{
Resistência contra ectoparasitas em bovinos da raça Crioula Lageana e meio-sangue Angus avaliada em condições naturais ${ }^{1}$
}

\author{
Cristina P. Cardoso ${ }^{2 *}$, Bruna F. Silva ${ }^{3}$, Daniele S. Gonçalves ${ }^{4}$, Nelson J. Tagliari ${ }^{5}$, \\ Mere E. Saito ${ }^{5}$ e Alessandro F.T. Amarante ${ }^{6}$
}

\begin{abstract}
Cardoso C.P., Silva B.F., Gonçalves D.S., Tagliari N.J., Saito M.E. \& Amarante A.F.T. 2014. [Resistence against ectoparasites in CriouloLageano and crossbred Angus cattle in southern Brazil under natural conditions.] Resistência contra ectoparasitas em bovinos da raça Crioula Lageana e meio-sangue Angus avaliada em condições naturais. Pesquisa Agropecuária Brasileira 34(2):141-146. Companhia Integrada de Desenvolvimento Agrícola de Santa Catarina, Rua Lauro Müller 936, Correia Pinto, SC 88535000, Brazil. E-mail: cristinaperito@yahoo.com.br

This study was carried out to evaluate the breed resistance against ectoparasites infestations in Crioula Lageana and crossbred Angus male calves under natural condition. Ten weaned and neutered male calves (6-8 months) of each group were kept together in winter and summer pastures in Monte Castelo, Santa Catarina State. Every 28 days, female ticks (Rhipicephalus (Boophilus) microplus) more than $4 \mathrm{~mm}$ long were counted on the right and left side of the body of each animal, as well as the D. hominis nodules. Coat thickness also was measured at each sampling and all animals were classified according coat color. Crioula Lageana group was less infested by $D$. hominis than crossbred Angus in five times and by ticks in the infestation peak $(\mathrm{P}<0.05)$. There were no differences in the distribution of the ticks and grubs between animal body sides. Dark-haired animal in both groups were the most susceptible.
\end{abstract}

INDEX TERMS: Innate response, ectoparasites, ticks, grubs, cattle.

RESUMO.- Este trabalho foi desenvolvido com o objetivo de avaliar a resistência aos ectoparasitas em bovinos jovens da raça Crioula Lageana e meio-sangue Angus em condições naturais. Foram utilizados 10 machos castrados em cada grupo, recém desmamados (6-8 meses) e mantidos sob as mesmas condições de manejo, em pastagens culti-

\footnotetext{
${ }^{1}$ Recebido em 2 de dezembro de 2013

Aceito para publicação em 27 de janeiro de 2014.

${ }^{2}$ Companhia Integrada de Desenvolvimento Agrícola de Santa Catarina (CIDASC), Rua Lauro Müller 936, Correia Pinto, SC 88535-000, Brasil. *Autor para correspondência: cristinaperito@yahoo.com.br

${ }^{3}$ Pós-Graduação em Ambiente e Saúde, Universidade do Planalto Catarinense (Uniplac), Av. Castelo Branco 170, Lages, SC 88509-900, Brasil. E-mail: brusilvabio@gmail.com

${ }^{4}$ Programa de Residência, Hospital Veterinário "Luis Quintiliano de Oliveira", Faculdade de Medicina Veterinária, Universidade Estadual Paulista (Unesp), Rua Clóvis Pestana 793, Araçatuba, SP 16050-680, Brasil. E-mail: danielesilvano@gmail.com

${ }^{5}$ Departamento de Medicina Veterinária, Centro de Ciências Agroveterinárias, Universidade do Estado de Santa Catarina (UDESC), Av. Luiz de Camões 2090, Lages, SC 88520-000, Brasil. E-mails: nelsonjt_vet@yahoo. com.br, mere.saito@udesc.br

${ }^{6}$ Departamento de Parasitologia, Instituto de Biociências, Unesp, Cx. Postal 510, Botucatu, SP 18618-970, Brasil. E-mail: amarante@ibb.unesp.br
}

vadas de inverno e verão, no município de Monte Castelo - SC, sofrendo infestação natural por ectoparasitas. A cada 28 dias, fêmeas de carrapatos (Rhipicephalus (Boophilus) microplus) com tamanho acima de $4 \mathrm{~mm}$ foram quantificadas nos dois lados do corpo de cada animal, bem como os nódulos com larvas de Dermatobia hominis. A espessura da capa do pelame foi também avaliada a cada coleta e os animais foram classificados quanto à coloração do pelame. Os animais da raça Crioula Lageana foram mais resistentes às infestações por $D$. hominis e R. microplus. Não houve diferença entre a disposição de carrapatos e bernes conforme os lados direito e esquerdo dos animais. Os animais de pelagem escura albergaram a maior porcentagem de ectoparasitas nos grupos avaliados.

TERMOS DE INDEXAÇÃO: Resposta inata, ectoparasitas, carrapatos, bernes, bovinos.

\section{INTRODUÇÃO}

A eficiência da exploração comercial de bovinos depende do seu potencial de produção, capacidade de adaptação ao ambiente e de sua resistência às doenças e parasitas. Referente aos ectoparasitas, o carrapato Rhipicephalus (Boo- 
philus) microplus e o berne (larvas de Dermatobia hominis) estão entre os mais importantes entraves para a pecuária brasileira (Silva et al. 2010). Sobretudo que no Brasil, as condições climáticas, amplamente favoráveis ao desenvolvimento desses parasitas, permitem que as populações se estabeleçam em praticamente todo o território nacional e ao longo de todos os meses do ano (Barci et al. 2009a).

A infestação por carrapatos se destaca como fator limitante para o desempenho dos animais, em consequência de suas ações espoliadora, mecânica e tóxica (Fraga et al. 2003), além de poder causar imunossupressão nos animais infestados (Jonsson 2006). Outro ponto a ressaltar é que a espécie R. microplus é vetora de Anaplasma marginale, Babesia bovis e Babesia bigemina, agentes da tristeza parasitária, doença que acomete muitos bovinos anualmente (Gonçalves 2000).

Os danos causados pela fase larval de D. hominis também são relevantes devido ao estresse que causam, mantendo os animais inquietos, os quais tentam constantemente lamber os nódulos, deixando de se alimentar (Barbosa et al. 2002). Além disso, as lesões na pele predispõem a ocorrência de infecções e/ou miíases secundárias. São estimadas perdas de milhões de dólares devido a essas infestações por D. hominis, com impacto na produção de leite, carne e principalmente na indústria coureira (Marques et al. 2000).

Artifícios curativos e profiláticos são empregados a fim de amenizar essas perdas. Contudo, o emprego de produtos químicos, por meio de banhos de aspersão, aplicação dorsal ou subcutânea e brincos impregnados, ainda é o método mais utilizado (Broce 2006). Adicionados aos custos elevados do tratamento, podem ser constatados prejuízos comerciais significativos, principalmente frente ao mercado externo, pelos resíduos de antiparasitários na carne e leite, como também pela contaminação ambiental (Spisso et al. 2009).

No campo, em pequenas propriedades, onde a assistência técnica é em geral precária, observa-se que essa situação é muito mais grave, pois na tentativa de manter o controle de parasitas e pelo fácil acesso aos antiparasitários, ocorre aumento crescente na dose utilizada, na frequência de tratamentos e até mesmo uso de formulações caseiras com misturas de princípios ativos (Barci et al. 2009b). Assim, o uso irracional e em larga escala prejudicam o controle futuro, em decorrência do rápido desenvolvimento de resistência dos parasitas aos medicamentos (Farias et al. 2008).

Atualmente, o controle de parasitas exclusivamente por agentes químicos é uma das principais preocupações científicas, econômicas e sociais (Patarroyo \& Lombana 2004). Fato relevante devido ao surgimento de parasitos resistentes aos antiparasitários e aos seus onerosos custos, bem como, pela crescente busca humana por uma vida saudável, usufruindo de alimentação segura e de qualidade, provinda de um sistema de agricultura sustentável (Waller \& Thamsborg 2004).

Mediante essa realidade, o conhecimento da resistência natural do hospedeiro aos ectoparasitas, torna-se a opção mais viável, ecologicamente correta e de fácil aplicação pe- los produtores, mesmo que, com resultados a médio e longo prazo (Hoste \& Torres-Acosta 2011).

Para facilitar a identificação dessas características, pesquisas têm sido realizadas buscando compreender os complexos mecanismos imunológicos e a identificação dos genes envolvidos na resistência, utilizando-se ferramentas da genética molecular que possibilitam a prospecção e o isolamento de tais genes (Martinez \& Machado 2002). Assim, o melhoramento genético poderá ser feito para a multiplicação dessas características no rebanho (Fraga et al. 2003), principalmente através do uso de reprodutores machos, tendo por base raças resistentes, o cruzamento entre essas raças ou a seleção de indivíduos resistentes dentro da própria raça (Hoste \& Torres-Acosta 2011).

Acredita-se que nas raças naturalizadas essas características de resistências sejam mais facilmente encontradas, devido ao seu processo de adaptação ambiental. Por outro lado, embora mais produtivas, as raças taurinas européias, devido à intensa seleção visando à produtividade, perderam suas características de adaptação, resistência a doenças e aos parasitas (Mariante 2007).

Crioula Lageana é uma raça naturalizada de bovinos, encontrada nos campos de Cima da Serra dos estados de Santa Catarina e Rio Grande do Sul. Trata-se de uma raça de duplo propósito (carne e leite), caracterizada por animais de boa produção, fêmeas com facilidade de parto e boa habilidade materna. São animais dotados de rusticidade, bem adaptados as planícies de altitude localizadas na região mais fria do Brasil (Camargo \& Martins 2005).

Neste contexto, o presente trabalho se propôs iniciar os estudos parasitológicos em animais da raça Crioula Lageana (Bos taurus), a fim de verificar se procede a informação empírica sobre a resistência desses animais aos ectoparasitas. No presente estudo, foi comparada a resistência de animais jovens da raça Crioula Lageana e meio-sangue Angus (B. taurus) às infestações por ectoparasitas.

\section{MATERIAL E MÉTODOS}

Foram utilizados 10 animais machos castrados da raça Crioula Lageana e 10 meio-sangue Angus (6-8 meses), criados a campo, ou seja, expostos aos parasitas desde o nascimento. Os animais denominados meio-sangue Angus eram oriundos de cruzamentos de touros Angus, puros por origem, com vacas de origem européia (cruzas Charolês, Hereford e Devon) e os animais da raça Crioula Lageana eram puros por origem.

Por ocasião da desmama, todos os animais passaram por exame clínico completo para exclusão de qualquer enfermidade e receberam tratamento com fosfato de levamisol 18,8\% (9,4 mg/kg, Ripercol ${ }^{\circledR} \mathrm{L} 150 \mathrm{~F}$, Fort Dodge) e fipronil 1\% (1mL/10kg, Topline ${ }^{\circledR}$, Merial), certificando-se que iniciariam o experimento livres de endoparasitas e ectoparasitas.

Os animais foram mantidos juntos e sob as mesmas condições de manejo, em pastagens cultivadas de inverno (Lolium sp., Avena sp. e Trifolium repens) e verão (Brachiaria sp., Sorghum sudanense e Axonopus catharinensis), no município de Monte Castelo, SC $\left(-26^{\circ} 27^{\prime} \mathrm{S}, 50^{\circ} 59^{\prime} 0\right)$, sofrendo infestação natural por ectoparasitas. 0 clima local, segundo a classificação de Koppen, é temperado úmido com verão temperado ( $\mathrm{Cfb}$ ), com temperatura anual média de $16^{\circ} \mathrm{C}$.

Os animais foram inspecionados, na parte da manhã, a cada 28 dias quando foi registrado o número e a localização de carrapatos 
e nódulos de larvas de Dermatobia hominis em ambos os lados do corpo do animal, totalizando 19 amostras (Julho2009 a Dezembro 2010). Para tanto, o corpo dos bovinos foi dividido em oito regiões: cauda, garupa, membros pélvicos, flancos, costelas, membros torácicos, região cervical e cabeça (Fig.1).

Imediatamente após a contagem dos nódulos de D. hominis, em cada coleta, foi feita a aplicação local de produto aerosol à base de vapona, supona e violeta genciana (Matabicheira Fortdodge ${ }^{\circledR}$ ) para evitar que o mesmo nódulo fosse recontado na coleta seguinte, visto que a queda das larvas de terceiro estágio ocorre entre o $33^{\circ}$ e $41^{\circ}$ dia após a infestação quando em condições climáticas ideais (Barbosa et al. 2003).

A avaliação, no que se refere aos carrapatos, foi baseada na contagem de fêmeas ingurgitadas com tamanho superior a $4 \mathrm{~mm}$. Quando constatada infestação, amostras dos parasitas foram coletadas e conservadas em álcool $70^{\circ}$ para posterior identificação em estereomicroscópio.

A espessura da capa do pelame também foi avaliada a cada coleta, utilizando-se uma régua introduzida suavemente na região da escápula direita de cada animal, mensurando a distância entre a superfície da capa do pelame e a base de inserção dos pelos.

Os animais foram classificados quanto à coloração do pelame (branca, amarela, vermelha e pintada - branco/vermelho e branco/preto).

Os valores acumulados para cada ectoparasita foram obtidos através da soma de exemplares constatados ao longo do período experimental em cada bovino.

As análises estatísticas dos dados obtidos nos grupos frente às infestações por carrapatos e bernes foram feitas através da análise de medidas repetidas (General Linear Models - SAS 9.2, 2008). Os dados foram transformados em $\log 10(\mathrm{x}+1)$. As correlações de Pearson entre os dados não transformados foram determinadas.

Este projeto foi submetido e aprovado pela Câmara de Ética em Experimentação Animal da Faculdade de Medicina Veterinária e Zootecnia, UNESP, Campus Botucatu, conforme Protocolo $\mathrm{n}^{-}$ 102/2008CEEA, datado de 08/04/2008.

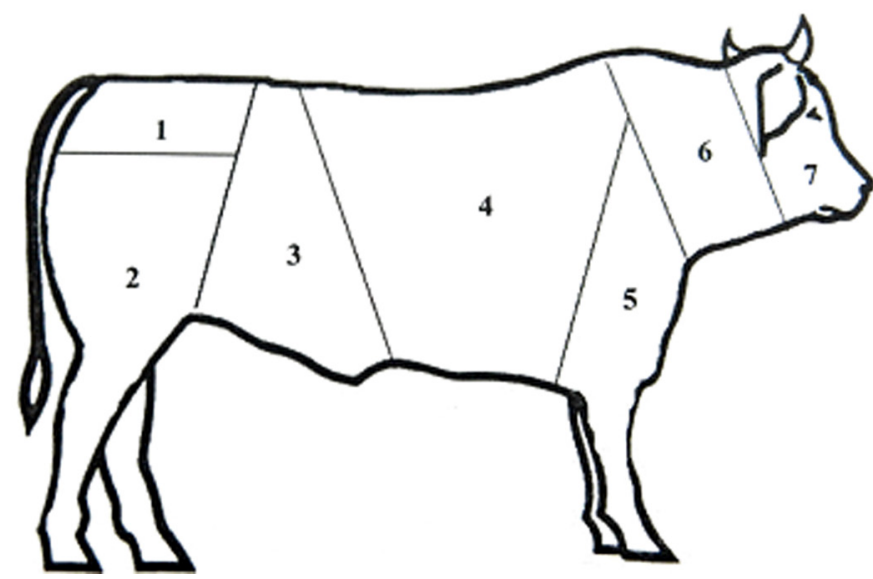

Fig.1. Divisão do corpo bovino utilizada para a distribuição dos ectoparasitas. Cauda, garupa (1), membro pélvico (2), flanco (3), costela (4), membro torácico (5), região cervical (6) e cabeça (7).

\section{RESULTADOS}

A raça Crioula Lageana mostrou valores numéricos, na maioria dos meses, menores do que o grupo meio-sangue Angus quanto à infestação por carrapatos e larvas de D. hominis (Quadro 1). Entretanto, houve diferença estatística
Quadro 1. Contagens médias de larvas de Dermatobia
hominis e teleóginas de Rhipicephalus (Boophilus) microplus nos grupos de bovinos da raça Crioula Lageana e meio-sangue Angus, naturalmente infestados, em Monte Castelo/SC, Brasil

\begin{tabular}{|c|c|c|c|c|}
\hline \multirow[t]{2}{*}{ Coleta } & \multicolumn{2}{|c|}{$\begin{array}{c}\text { Dermatobia } \\
\text { hominis } \\
\text { média (mínima - máxima) }\end{array}$} & \multicolumn{2}{|c|}{$\begin{array}{l}\text { Rhipicephalus (Boophilus) } \\
\text { microplus } \\
\text { média (mínima - máxima) }\end{array}$} \\
\hline & $\begin{array}{c}\text { Crioula } \\
\text { Lageana }\end{array}$ & $\begin{array}{c}\text { Meio-sangue } \\
\text { Angus }\end{array}$ & $\begin{array}{c}\text { Crioula } \\
\text { Lageana }\end{array}$ & $\begin{array}{c}\text { Meio-sangue } \\
\text { Angus }\end{array}$ \\
\hline 23 Out. 2009 & $1,8(0-5)$ & $4,8(0-19)$ & 0 & 0 \\
\hline 18 Nov. 2009 & $5,7(1-21)$ & $9,7(0-43)$ & 0 & 0 \\
\hline 16 Dez. 2009 & $9,0(0-31)$ & $6,6(0-28)$ & 0 & 0 \\
\hline 13 Jan. 2010 & $4,0(0-9)$ & $9,1(0-40)$ & 0 & 0 \\
\hline 10 Fev. 2010 & $3,8(0-19)$ & $16,5(0-88)$ & $0,2(0-1)$ & $0,3(0-2)$ \\
\hline 10 Mar. 2010 & $1,1(0-6)$ & $13,4(0-69)$ & 0 & 0 \\
\hline 08 Abr. 2010 & 0 & $5,0(0-39)$ & $0,3(0-1)$ & $0,6(0-5)$ \\
\hline 05 Mai. 2010 & 0 & $4,9 *(0-20)$ & $0,6(0-2)$ & $4,4^{*}(0-13)$ \\
\hline 03 Jun. 2010 & $1,5(0-8)$ & $4,1(0-12)$ & $0,1(0-1)$ & $0,1(0-1)$ \\
\hline 02 Jul. 2010 & $0,7(0-5)$ & $1,2(0-5)$ & 0 & 0 \\
\hline 30 Jul. 2010 & 0 & $0,1(0-1)$ & 0 & 0 \\
\hline 26 Set. 2010 & $0,1(0-1)$ & $2,2 *(0-6)$ & 0 & $0,3(0-2)$ \\
\hline 22 Out. 2010 & $0,4(0-2)$ & $8,4^{*}(0-27)$ & $1,3(0-5)$ & $0,4(0-2)$ \\
\hline 20 Nov. 2010 & $0,9(0-4)$ & $15,4^{*}(0-48)$ & $0,7(0-1)$ & $2,2(0-12)$ \\
\hline 5 Dez. 2010 & $0,3(0-2)$ & $7,5^{*}(0-27)$ & $0,2(0-1)$ & 0 \\
\hline
\end{tabular}

Para cada espécie de parasita, as médias com diferença estatística significativa entre as raças nas diferentes coletas (linhas) estão sinalizadas pelo asterisco $\left(^{*}\right)$.

nas contagens de carrapatos entre as raças avaliadas apenas no mês de maio/2010 e em cinco meses em relação à contagem de larvas de Dermatobia hominis.

As médias dos valores acumulados para contagem de carrapatos foram de 3,4 exemplares por animal nos Crioulos e 8,3 nos meio-sangue Angus. Referente à contagem de nódulos de berne, as médias acumuladas foram de 29,3 e 108,9 nódulos por animal, respectivamente para os grupos Crioulo e meio-sangue Angus.

Todos os animais, em algum momento do período experimental, foram infestados tanto por larvas de D. hominis como por fêmeas adultas de carrapato, sendo que ao longo de todo o período experimental foi identificado apenas carrapatos da espécie Rhipicephalus microplus.

Grande variação individual na quantificação de ectoparasitas foi constatada entre os animais do mesmo grupo racial, sendo que os valores para as contagens de carrapatos variaram de zero a cinco nos Crioulos e de zero a 13 exemplares por animal nos indivíduos meio-sangue Angus, enquanto que para as contagens de nódulos de berne foram de zero a 31 e de zero a 88 nódulos por animal, respectivamente na raça Crioula Lageana e no grupo meio-sangue Angus.

Dois animais Crioulos e um único indivíduo meio-sangue Angus apresentaram, respectivamente, 48,12 e 40,96\% da contagem total de bernes. No grupo Crioulo um animal albergou apenas duas larvas ao longo do estudo, bastante diferente do grupo meio-sangue Angus, em que os cinco animais menos infestados apresentaram contagem que variou de oito a 31 nódulos, valores compatíveis com os máximos constatados na raça Crioula Lageana.

Os animais meio-sangue Angus mais infestados por carrapatos foram os mesmos que apresentaram maiores 
contagens de nódulos de berne, sendo observada alta correlação positiva $(0,89 ; \mathrm{P}<0,01)$ entre os valores cumulativos para as infestações por esses ectoparasitas. No grupo Crioulo isso não ocorreu, constatando-se correlação negativa moderada $(-0,44 ; \mathrm{P}>0,05)$ entre essas variáveis.

As maiores contagens de carrapatos ocorreram no outono (Maio de 2010) e primavera (Novembro de 2010 - Crioulos e Dezembro de 2010 - meio-sangue Angus). No entanto, a infestação foi baixa e pouco significativa como problema sanitário para os animais ao longo dos meses avaliados.

Quanto à distribuição de ectoparasitas, não houve diferença em relação aos lados direito e esquerdo dos animais investigados. Na infestação por carrapatos, os membros pélvicos abrigaram a maioria dos exemplares $(61,77 \%)$ na raça Crioula Lageana. Nos indivíduos meio-sangue Angus a maior infestação ocorreu na região cervical, com $28,92 \%$, apresentando distribuição mais uniforme entre as diferentes partes do corpo (Quadro 2). No que se refere à concentração de nódulos de larvas de $D$. hominis, a região dos membros anteriores com $53,93 \%$ e das costelas com $45,27 \%$ foram, respectivamente, as preferenciais no grupo Crioulo e meio-sangue Angus.

Os animais meio-sangue Angus (cinco exemplares) de pelagem vermelha albergaram $90,73 \%$ dos nódulos de $D$.

Quadro 2. Distribuição dos ectoparasitas conforme as regiões do corpo dos animais na raça Crioula Lageana e meio-sangue Angus, naturalmente infestados, em Monte Castelo/SC, Brasil

\begin{tabular}{lccccc}
\hline Região corporal & \multicolumn{2}{c}{$\begin{array}{c}\text { Nódulos de larvas de } \\
\text { Dermatobia hominis }\end{array}$} & & \multicolumn{2}{c}{$\begin{array}{c}\text { Boophilus } \\
\text { microplus }\end{array}$} \\
\cline { 2 - 3 } \cline { 5 - 6 } & $\begin{array}{c}\text { Crioula } \\
\text { Lageana \% }\end{array}$ & $\begin{array}{c}\text { Meio-sangue } \\
\text { Angus \% }\end{array}$ & & $\begin{array}{c}\text { Crioula } \\
\text { Lageana \% }\end{array}$ & $\begin{array}{c}\text { Meio-sangue } \\
\text { Angus \% }\end{array}$ \\
\hline Cabeça & 7,17 & 2,29 & & 0 & 0 \\
R. cervical & 10,58 & 10,01 & & 8,82 & 28,92 \\
M. torácicos & 53,93 & 27,18 & & 14,71 & 26,51 \\
Costelas & 21,16 & 45,27 & & 2,94 & 6,02 \\
Flancos & 2,73 & 6,98 & & 0 & 18,07 \\
M. pélvicos & 3,75 & 5,05 & & 61,77 & 19,28 \\
Garupa & 0,68 & 2,39 & & 8,82 & 1,20 \\
Cauda & 0 & 0,83 & & 2,94 & 0
\end{tabular}

hominis e 78,31\% dos carrapatos. Nos indivíduos Crioulos, devido à pelagem geralmente pintada, considerou-se como escuros os animais que tinham coloração vermelha em mais de $90 \%$ da superfície corporal, sendo que esses animais (quatro indivíduos) abrigaram 45,73\% dos nódulos e $44,12 \%$ das teleóginas. Cabe ressaltar que as tonalidades de vermelho eram semelhantes em alguns animais, porém, alguns indivíduos meio-sangue Angus apresentavam tonalidades mais escuras (Fig.2). Ao que parece, a variação dentro das tonalidades de vermelho não influenciou no aumento do parasitismo, visto que o animal mais escuro foi o que albergou menor quantidade de larvas entre os animais de pelagem vermelha.

Ao analisar os dados referentes à variável espessura da capa de pelame, constatou-se que nos meses de julho e agosto de 2009 e entre abril e outubro de 2010 os dados diferiram estatisticamente entre as raças, sendo que os animais meio-sangue Angus apresentaram as maiores medidas (médias de 0,13-1,85cm) em relação aos Crioulos (médias de 0,11-0,98cm).

Foi constatada interação significativa entre tempo e grupo para as variáveis espessura de pelame e contagens de carrapato e berne, demonstrando diferença no padrão de distribuição desses valores conforme o grupo racial.

\section{DISCUSSÃO}

Os dados obtidos dos animais da raça Crioula Lageana tanto frente ao parasitismo por larvas de $D$. hominis quanto por carrapatos sugerem maior resistência desta raça nas infestações por ectoparasitas. Acredita-se que o desafio imposto pelas condições climáticas extremas durante os rigorosos invernos da região Sul, com sucessivas geadas e nevascas, a falta de alimento, os predadores e o próprio abandono nas grandes extensões rurais, contribuíram para a formação de uma raça adaptada às condições ambientais das regiões de altitude e ao clima subtropical (Camargo \& Martins 2005), bem como acumularam, após quase cinco séculos de seleção natural, características referentes à resistência às doenças e aos parasitas (Mariante et al. 2005).

Vários trabalhos foram desenvolvidos objetivando ca-

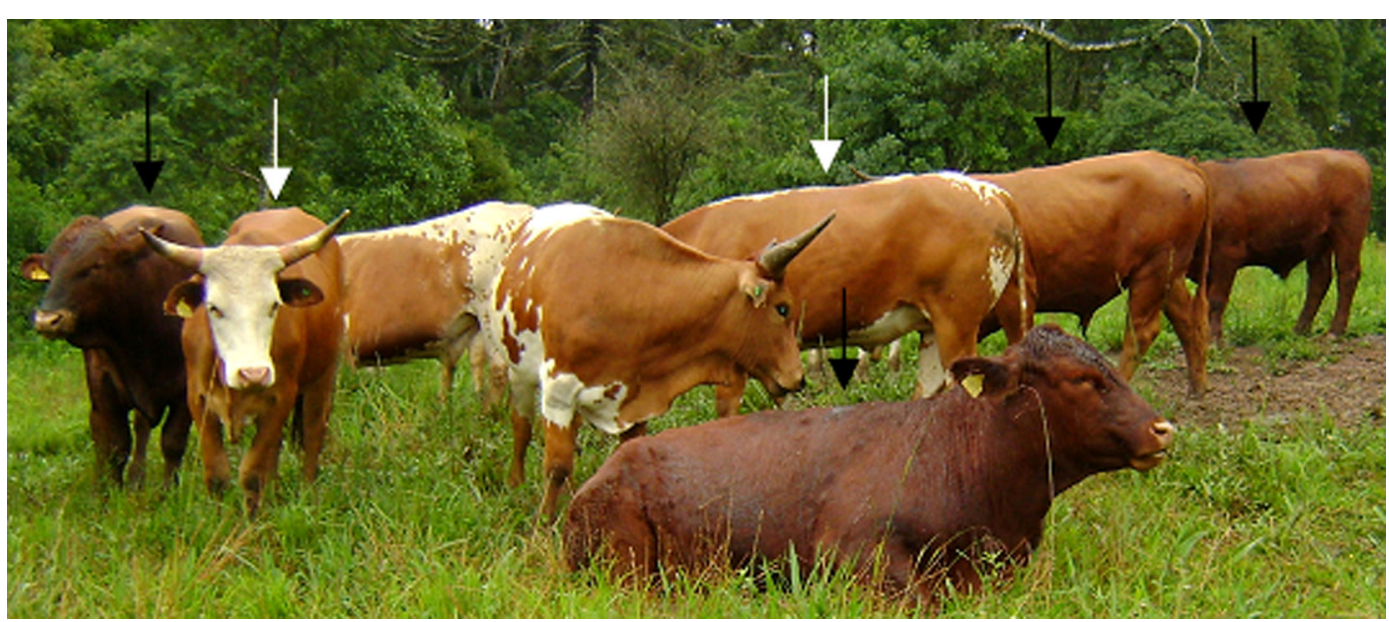

Fig.2. Diferentes tonalidades da cor vermelha observadas nos animais da raça Crioula Lageana (setas brancas) e meio-sangue Angus (setas pretas). 
racterizar a resistência aos ectoparasitas em diferentes raças e seus cruzamentos, principalmente entre bovinos de origem européia e zebuínos. Neste contexto, em infestações naturais por carrapatos, Oliveira et al. (1989) observaram maior resistência nos animais da raça Nelore quando comparados a indivíduos Canchim. Ainda, ao avaliar o número de teleóginas quantificadas em infestação artificial, Silva et al. (2007) encontraram baixa resistência às infestações nos animais Angus x Nelore e Simental x Nelore, sendo intermediária no grupo Canchim x Nelore e alta nos indivíduos Nelore. Nestes trabalhos citados acima, constata-se que os animais com maior grau de sangue de raças européias estão mais predispostos aos ectoparasitas. Contudo, por terem sido utilizados somente animais $B$. taurus neste experimento, podemos conferir o mérito de maior resistência à raça Crioula Lageana frente às infestações por carrapatos (Maio 2010) e bernes (Maio, Set.-Dez 2010). Cabe ressaltar que se os animais estivessem em ambiente com maior contaminação ou sob infestações artificiais por carrapatos, talvez, essa característica seria melhor evidenciada, pois durante todo o estudo foi constatada baixa infestação, possivelmente, pela utilização de rodízio de piquetes e por uso de área despovoada de bovinos por seis anos.

Em infestações naturais por carrapato, berne e mosca-dos-chifres, Silva et al. (2010) observaram que, em geral, os animais Nelore foram os mais resistentes ao parasitismo pelo carrapato e animais Angus x Nelore foram os mais parasitados por berne e mosca-dos-chifres. No entanto, o grau de infestação nos quatro grupos avaliados variou em função do ano-época. No presente trabalho essa variação também foi constatada no parasitismo por carrapatos e bernes, sendo que nos animais Crioulos as maiores médias para contagens de bernes foram verificadas até a oitava coleta e após esta data não ultrapassaram a média de 1,5 nódulos/animal. Fato este que não ocorreu no grupo meio-sangue Angus, em que as médias foram baixas somente no inverno, aumentando posteriormente. Estes resultados sugerem que os animais Crioulos adquiriram imunidade após as primeiras infestações, o que não foi observado no grupo meio-sangue Angus.

Gomes et al. (1996) constataram que a raça sintética Ibagé foi a mais infestada por larvas de D. hominis quando comparada com Nelore puro e suas cruzas com Charolês, Chianina e Fleckvieh. No entanto, encontraram diferenças significativas entre indivíduos da mesma raça/cruzamento. A variação individual também foi constatada neste estudo, que mostrou que 10 e $20 \%$ dos animais meio-sangue Angus e Crioulos, respectivamente, abrigavam mais de $40 \%$ das larvas quantificadas em cada grupo.

No que se refere ao grau de infestação por ectoparasitas nas diferentes regiões e estações do ano no Brasil, a literatura apresenta resultados variados devido aos seus diversos climas e ambientes. As condições climáticas e a latitude são os principais fatores reguladores do ciclo biológico dos ixodídeos, tendo a temperatura o papel dominante na duração das fases de vida livre e a latitude, através do fotoperíodo, na sazonalidade por ação direta na diapausa (Brito et al. 2006). No presente estudo, o ciclo dos carrapatos no período experimental se manteve, com ausência apenas entre julho e setembro de 2010, período de inverno, que na região se caracteriza por ser bastante rigoroso com temperaturas negativas e fortes geadas.

No Estado de Santa Catarina, no município de Lages, o qual apresenta clima semelhante ao de Monte Castelo, Honer et al. (1993) observaram médias mensais de contagem de teleóginas acima de 100 na maioria dos meses do ano, exceto entre agosto e novembro. Pela similaridade de clima, pode-se deduzir que, na maior parte do ano, as condições ambientais neste experimento foram favoráveis ao ciclo de vida livre do carrapato. Assim, novos estudos são sugeridos, porém, em ambientes contaminados ou mesmo com infestações experimentais a fim de se confirmar essa tendência de resistência da raça Crioula Lageana aos carrapatos.

Ainda no Planalto Catarinense, Bellato et al. (1986) observaram dados diferentes aos deste estudo quanto a quantidade de nódulos/animal, os quais encontraram infestações durante todo o ano, com maior intensidade nos meses de verão e média de parasitismo de aproximadamente 80 bernes/indivíduo. Diferindo em muito das médias máximas observadas no grupo susceptível (meio-sangue Angus), as quais não chegaram a apresentar 17 nódulos nos picos de infestação.

Nódulos de $D$. hominis não foram observados em ambas as raças nos três meses iniciais (Jul.-Set. 2009), possivelmente, devido ao efeito residual do tratamento inicial com fipronil, acrescido da baixa contaminação da área e ao inverno, o que voltou a ocorrer em setembro de 2010. Na raça Crioula Lageana a ausência ainda ocorreu nos meses de abril, maio e agosto de 2010 , coincidindo com as temperaturas mais amenas e frias, entretanto, reforçando sua característica de maior resistência. Dados similares em parte aos resultados de Mozzaquatro \& Sanavria (2003), que observaram que as infestações foram mais intensas nas épocas quente e mais baixas ou ausentes nos meses mais frios em Santa Maria/RS.

Referente à localização, segundo Pinto et al. (2002), os membros torácicos, paletas e costelas totalizaram 80,06\% da localização dos nódulos de berne em vacas holandesas preto e branco em Palotina/PR, dados próximos aos observados neste trabalho nos grupos meio-sangue Angus $(72,45 \%)$ e Crioula Lageana $(75,09 \%)$. Corroborando Mozzaquatro \& Sanavria (2003), que salientam que grande perda do couro ocorre porque as partes nobres aproveitadas são justamente as craniais e mais acometidas pelos parasitas. Entretanto, os resultados obtidos neste trabalho diferem dos achados de Pinto et al. (2002) em relação ao parasitismo conforme o lado do corpo do animal, os quais constataram que a presença de nódulos no lado esquerdo foi maior, abrigando 69,36\% da contagem total de bernes, diferença não observada em ambos os grupos frente ao parasitismo por carrapatos e bernes.

Os animais de pelagem de coloração escura foram mais acometidos pelos ectoparasitas tanto no grupo da raça Crioula Lageana como no meio-sangue Angus, dados semelhantes aos de Andrade et al. (1998), que ao encontrarem maior suscetibilidade ao carrapato nos animais de colorações mais escuras, acrescentam que provavelmente isso 
se deva pela queda no nível de resistência desses animais em virtude do maior estresse calórico a que estão sujeitos. Entretanto, nesse mesmo sentido, estudos de Fraga et al. (2003) não mostraram esta variação.

Quanto à espessura da capa do pelame, os menores valores encontrados nos animais Crioulos reafirmam as observações de Fraga et al. (2003), que salientam que animais com menores espessuras de capa de pelame são mais adaptados e têm menores infestações. Assim como as pelagens claras, as capas de pelame mais finas exercem ainda menor atração de insetos transportadores dos ovos do berne (Moya-Borja 2003). Salienta-se que as diferenças na espessura de pelame entre os grupos Crioulo e meio-sangue Angus coincidiram com a maior resistência dos animais Crioulos em maio de 2010, para ambos ectoparasitas e outubro de 2010 para berne. Fatos que indicam sua influência na resistência/susceptibilidade dos animais avaliados.

Assim, nas condições em que foi conduzido o experimento, conclui-se, preliminarmente, que os animais da raça Crioula Lageana foram mais resistentes que os meio-sangue Angus frente às infestações por bernes e carrapatos e que os indivíduos de pelagem mais escura, em ambas as raças, foram mais susceptíveis aos ectoparasitas, não havendo diferença na localização dos ectoparasitas quanto ao lado do animal. Infestações experimentais em condições controladas se fazem necessárias para a confirmação desses resultados.

\section{REFERÊNCIAS}

Andrade A.B.F., Silva R.G., Costa A.J., Rocha U.F. \& Landim V.J.C. 1998. Genetic and environmental aspects of the resistance of zebu cattle to the tick Boophilus microplus. Proc. $6^{\text {th }}$ World Congress on Genetics Applied to Livestock Production, Armildade, n.27, p.339-342.

Barbosa C.G., Sanavria A. \& Barbosa M.D.P.R.C. 2003. Alterações hematológicas em bovinos infestados experimentalmente com larvas de Dermatobia hominis (Diptera: Cuterebridae). Revta Bras. Parasitol. Vet. 12:6167.

Barbosa C.G., Sanavria A. \& Barbosa M.D.P.R.C. 2002. Fase parasitária e alterações clínicas em bovinos infestados experimentalmente com larvas de Dermatobia hominis (Díptera: Cuterebridae). Parasitol. Latinoam. 57:15-20.

Barci L.A.G., Almeida J.E.M., Nogueira A.H.C. \& Prado A.P. 2009a. Determinação da CL90 e TL90 do isolado IBCB66 de Beauveria bassiana (Ascomycetes: Clavicipitaceae) para o controle de Rhipicephalus (Boophilus) microplus (Acari: Ixodidae). Revta Bras. Parasitol. Vet. 18(Supl.1):34-39.

Barci L.A.G., Wenzel I.M., Almeida J.E.M., Nogueira A.H.C. \& Prado A.P. 2009b. Compatibilidade de isolados de Beauveria bassiana (Ascomycetes: Clavicipitaceae) com carrapaticidas químicos utilizados no controle do carrapato dos bovinos. Rev Bras. Parasitol. Vet. 18(Supl.1):63-68.

Bellato V., Paloschi C.G., Sartor A.A., Ramos C.I. \& Souza A.P. 1986. Variação sazonal das larvas da mosca do berne em bovinos no Planalto Catarinense. Comum. Téc.101, Empasc, Florianópolis, p.1-7.

Brito L.G., Silva Netto F.G., Oliveira M.C.S. \& Barbieri F.S. 2006. Bio-ecologia, importância médico-veterinária e controle de carrapatos, com ênfase no carrapato de bovinos, Rhipicephalus (Boophilus) microplus. Documentos 104, Embrapa Rondônia, Porto Velho. 21p.

Broce A.B. 2006. Ectoparasite control. Vet. Clin. North Am., Food Anim. Pract. 22:463-474.

Camargo M.A.R. \& Martins V.M.V. Raça bovina Crioula Lageana, um patrimônio genético. Hora Vet. 24(143):61-64.
Farias N.A., Ruas J.L. \& Santos T.R.B. 2008. Análise da eficácia de acaricidas sobre o carrapato Boophilus microplus, durante a última década, na região sul do Rio Grande do Sul. Ciência Rural 38:1700-1704.

Fraga A.B., Alencar M.M., Figueiredo L.A., Razook A.G. \& Cyrillo J.N.S.G. 2003. Análise de fatores genéticos e ambientais que afetam a infestação e fêmeas bovinas da raça caracu por carrapatos (Boophilus microplus). Revta Bras. Zootec. 32(Supl.1):1578-1586.

Gomes A., Honer M.R. \& Silva R.L. 1996. Intensidade parasitária de larvas de Dermatobia hominis (L. Jr 1781) (Díptera: Cuterebridae) em bovinos de diferentes raças criadas extensivamente na região de cerrado em Mato Grosso do Sul. Revta Bras. Parasitol. Vet.5:103-106.

Gonçalves P.M. 2000. Epidemiologia e controle da tristeza parasitária bovina na região sudeste do Brasil. Ciência Rural 30:187-194.

Honer M.R., Paloschi C.G., Souza A.P., Ramos C.I. \& Beck A.A.H. 1993. Epidemiologia e controle do carrapato dos bovinos Boophilus microplus no Estado de Santa Catarina. Bolm Téc. 62, Epagri, Florianópolis. 26p.

Hoste H. \& Torres-Acosta J.F.J. 2011. Non chemical control of helminths in ruminants: adapting solutions for changing worms in a changing world. Vet. Parasitol. 180:144-154.

Jonsson N.N. 2006. The productivity effects of cattle tick (Boophilus microplus) infestation on cattle, with particular reference to Bos indicus cattle and their crosses. Vet. Parasitol. 137:1-10.

Mariante A.S. 2007. Os benefícios de conservar os recursos genéticos. 3 ago. 2007. Disponível em <http://www.cenargen.embrapa.br/cenargenda/pdf2007/beneficios_conservar_rec_geneticos.pdf> Acesso em 24 out. 2013.

Mariante A.S., Albuquerque M.S.M., Egito A.A., Paiva S.R. \& Castro S.T.R. 2005. Situação atual dos grupamentos raciais em vias de extinção das diferentes espécies animais no Brasil. Anais/palestras $16^{\circ}$ Congresso Brasileiro de Reprodução Animal, Goiânia. (CD ROM)

Marques F.A.C. , Yamamura M.H. \& Vidotto O. 2000. Lesões no couro bovino causadas pelos principais ectoparasitas nas regiões Noroeste do Estado do Paraná e Sudoeste do Estado do Mato Grosso. Semina, Ciênc. Agrárias 21:33-39.

Martinez M.L. \& Machado M.. 2002. Programa genoma brasileiro de bovinos e suas perspectivas de aplicações práticas. Anais 4ํㅗำ Simpio Nacional de Melhoramento Animal, Campo Grande, MS. (CD-ROM)

Moya-Borja G.E. 2003. Erradicação ou manejo integrado das miíases neotropicais da Américas? Pesq. Vet.Bras. 23:131-138.

Mozzaquatro F.D. \& Sanavria 2003. An epidemiological study of Dermatobia hominis (Díptera: Cuterebridae) on dairy cattle in a community of Santa Maria, Rio Grande do Sul State, Brazil. Parasitol. Latinoam. 58:8082

Oliveira G.P., Alencar M.M. \& Freitas A.R. 1989. Resistência de bovinos ao carrapato Boophilus microplus II. Infestação natural. Pesq. Agropec. Bras. 24:1267-1271.

Patarroyo J.H. \& Lombana C.G. 2004. Resposta imune a vacinas sintéticas anti Boophilus microplus. Revta Bras. Parasitol. Vet. 13(Supl.1):129-134.

Pinto S.B., Soccol V.T., Vendruscolo E., Rochadelli R., Ribeiro P.B., Freitag A., Henemann C. \& Uemura, M. 2002. Bioecologia de Dermatobia hominis (Linnaeus Jr., 1781) em Palotina, Paraná, Brasil. Ciência Rural 32:821827.

Silva A.M., Alencar M.M., Regitano L.C.A. \& Oliveira M.C.S. 2010. Infestação natural de fêmeas bovinas de corte por ectoparasitas na Região Sudeste do Brasil. Revta Bras. Zootec. 39:1477-1482.

Silva A.M., Alencar M.M., Regitano L.C.A., Oliveira M.C.S. \& Barioni Júnior W. 2007. Artificial infestation of Boophilus microplus in beef cattle heifers of four genetic groups. Gen. Mol. Biol. 30:1150-1155.

Spisso B.F., Nóbrega A.W. \& Marques M.A.S. 2009. Resíduos e contaminantes químicos em alimentos de origem animal no Brasil: histórico, legislação e atuação da vigilância sanitária e demais sistemas regulatórios. Ciência e Saúde Coletiva 14:2091-2106.

Waller P.J. \& Thamsborg S.M. 2004. Nematode control in "green" ruminant production systems. Trends in Parasitology 20:493-497. 